\title{
SUBJECTIVE RISK ESTIMATION OF THE RARE EVENT
}

\author{
Hoang Nguyen \\ Gdynia Maritime University, Department of Engineering Sciences \\ Morska Street 81-87, 81-225 Gdynia, Poland \\ tel.: +48585586306 \\ e-mail:h.nguyen@wm.umg.edu.pl
}

\begin{abstract}
In the safety engineering, the most frequently disadvantage in risk estimation is the lack of data. In such cases, we have to rely on subjective estimations made by persons with practical knowledge in the field of interest, i.e. experts. However, in some realistic situations, they may have uncertainty in the perceiving and evaluation of the problem considered or limited knowledge of the rare events, such as the consequences of the seagoing ship propulsion failures. The probabilistic models of the risk estimation turn out to be insufficient in modelling the subjective uncertainty. The fuzzy methods are viewed to be powerful in dealing with ambiguity and uncertainty that can be used to handle with the subjective estimation. This article addresses the intuitionistic fuzzy method in the subjective estimation of the ship propulsion failure consequences as rare event risk. In the article, a subjective model of the ship propulsion risk is developed as scenarios of the different subsequent consequences of loss of ship propulsion function until a seriously severe accident resulting in loss of seaworthiness. The model proposes an approach combining AHP method and intuitionistic fuzzy method to assess the occurrence probability and severe probability of these rare events based on the expert opinions. In order to show the applicability of the proposed model, a study case of the propulsion risk of the container carrier operating on the North Atlantic lines is conducted.
\end{abstract}

Keywords: rare event, subjective risk estimation, intuitionistic fuzzy set, ship propulsion risk

\section{Introduction}

In the risk analyses, there exist events occurring so rarely that they are considered unlikely. However, occurrence of such events is possible. We describe them as "improbable but possible", namely rare events (RE), as they are often essential in the risk analyses. Damage occurring as a consequence of the loss of ship propulsion function is a rare event. The probability of such event within a specific time interval is defined as ship propulsion risk (PR). Lack of statistical or historical data connected with the PR events has been a frequently met circumstance and we must rely on the subjective, say expert estimations in the analyses [7]. Rare event estimation consists in the objective probability estimation of the conditions in which the event can happen and next in the elicitation of its subjective conditional probability in that condition [12]. An example of the subjective risk estimation of the PR with the severe accidents as REs will be presented below. The object considered will be a virtual container carrier operating in the North Atlantic with the ship propulsion system (PS) treated as an anthropic technical system.

\section{Models of the consequences of loss of ship propulsion function}

Loss of the ship propulsion function can occur due to a PS failure or to a human error (HE) in the system usage process. This event occurring in a ship operational process is an immediate catastrophic failure (ICF). Based on the IMO code [10], a set $\mathrm{C}$ of the damage severity categories as an effect of ICF event is presented in Tab. 1. In shipping, they are called marine accidents. It is a complete set of disjoint categories ordered by severity. The damage in consequence of an ICF event as an initiating event may occur in the following ship operational states:

- sailing in heavy weather $\left(\mathrm{S}_{1}\right)$, 
Tab. 1. Set $C$ of damage (marine accident) severity categories as an effect of ICF event

\begin{tabular}{|c|l|}
\hline Symbol & \multicolumn{1}{|c|}{ Description } \\
\hline $\mathrm{C} 1$ & $\begin{array}{l}\text { BCWM - Very severe marine accident. Loss of ship, loss of human life and/or heavy marine } \\
\text { environment pollution. }\end{array}$ \\
\hline C2 & $\begin{array}{l}\text { CWM - Severe marine accident. Fire, explosion, grounding, collision, contact, storm damage, } \\
\text { ice damage, hull fracture (or suspected fracture), marine environment pollution (regardless of the } \\
\text { intensity), damage resulting in loss of seaworthiness, necessity of towing or of assistance from } \\
\text { shore. }\end{array}$ \\
\hline $\mathrm{C} 3$ & $\begin{array}{l}\text { IM-I - Marine incident I - prolonged temporary loss of propulsion function. Repair by ship own } \\
\text { means and restarting the propulsion system. Ship propulsion function is not fully restored. }\end{array}$ \\
\hline $\mathrm{C} 4$ & $\begin{array}{l}\text { IM-II - Marine incident II - prolonged temporary loss of propulsion function. Repair by ship } \\
\text { own means and restarting the propulsion system. Ship propulsion function is fully restored. }\end{array}$ \\
\hline $\mathrm{C} 5$ & IM-III - Marine incident III - short loss of ship propulsion function. No need of repair. \\
\hline
\end{tabular}

- manoeuvres and/or approaching or leaving the port $\left(\mathrm{S}_{2}\right)$,

- sailing in open sea $\left(\mathrm{S}_{3}\right)$,

- sailing in restricted waters (straits, gulfs) $\left(\mathrm{S}_{4}\right)$,

- sailing in restricted inland waterways (canals, locks, rivers, lakes) $\left(\mathrm{S}_{5}\right)$.

The presented in Tab. 2, set of operational states has been selected by experts from the viewpoint of ship hazard in the ICF event situation. In the Tab. 2, rows represent branches of the event tree (ET), not presented expressly in the article. Damage connected with particular sequences is called partial damage.

Tab. 2. Scenario sequences of events leading to ICF severe consequences $C$, where $Y=y e s, N=$ no

\begin{tabular}{|c|c|c|c|c|c|c|c|}
\hline \multirow{2}{*}{$\begin{array}{c}\text { Initiating } \\
\text { event }\end{array}$} & \multicolumn{5}{|c|}{ Environmental states } & \multirow{2}{*}{ Damage C } & \multirow{2}{*}{ Logical expressions of sequences } \\
\hline & $\mathrm{S}_{1}$ & $\mathrm{~S}_{2}$ & $\mathrm{~S}_{3}$ & $\mathrm{~S}_{4}$ & $\mathrm{~S}_{5}$ & & \\
\hline \multirow{7}{*}{ ICF } & $\mathrm{Y}$ & $\mathrm{Y}$ & $\mathrm{N}$ & $\mathrm{N}$ & $\mathrm{N}$ & $\mathrm{Y}$ & $\mathrm{C}^{(1)}=\mathrm{ICF} \cap \mathrm{S}_{1} \cap \mathrm{S}_{2} \cap \mathrm{C}$ \\
\hline & $\mathrm{Y}$ & $\mathrm{N}$ & $\mathrm{Y}$ & $\mathrm{N}$ & $\mathrm{N}$ & $\mathrm{Y}$ & $\mathrm{C}^{(2)}=\mathrm{ICF} \cap \mathrm{S}_{1} \cap \mathrm{S}_{3} \cap \mathrm{C}$ \\
\hline & $\mathrm{Y}$ & $\mathrm{N}$ & $\mathrm{N}$ & $\mathrm{Y}$ & $\mathrm{N}$ & $\mathrm{Y}$ & $\mathrm{C}^{(3)}=\mathrm{ICF} \cap \mathrm{S}_{1} \cap \mathrm{S}_{4} \cap \mathrm{C}$ \\
\hline & $\mathrm{Y}$ & $\mathrm{N}$ & $\mathrm{N}$ & $\mathrm{N}$ & $\mathrm{Y}$ & $\mathrm{Y}$ & $\mathrm{C}^{(4)}=\mathrm{ICF} \cap \mathrm{S}_{1} \cap \mathrm{S}_{5} \cap \mathrm{C}$ \\
\hline & $\mathrm{N}$ & $\mathrm{Y}$ & $\mathrm{N}$ & $\mathrm{N}$ & $\mathrm{N}$ & $\mathrm{Y}$ & $\mathrm{C}^{(5)}=\mathrm{ICF} \cap \mathrm{S}_{2} \cap \mathrm{C}$ \\
\hline & $\mathrm{N}$ & $\mathrm{N}$ & $\mathrm{N}$ & $\mathrm{Y}$ & $\mathrm{N}$ & $\mathrm{Y}$ & $\mathrm{C}^{(6)}=\mathrm{ICF} \cap \mathrm{S}_{4} \cap \mathrm{C}$ \\
\hline & $\mathrm{N}$ & $\mathrm{N}$ & $\mathrm{N}$ & $\mathrm{N}$ & $\mathrm{Y}$ & Y & $\mathrm{C}^{(7)}=\mathrm{ICF} \cap \mathrm{S}_{5} \cap \mathrm{C}$ \\
\hline
\end{tabular}

Considered are consequences of the ICF event from the $\mathrm{C}$ subset. More details of the ICF event and of the PR analysis can be found in reference [2].

The ICF initiating event and some partial events of damage occurrence $\mathrm{C}(\mathrm{i}),(\mathrm{i}=1,2, \ldots, 7)$, are obviously dependent. Strong storms and even hurricanes are frequent in the North Atlantic [1], [5]. In the strong storm $S_{1}$ state, waves and wind cause rolling and pitching and impacts of water on the ship hull and equipment, initiating destruction processes. They also cause abrupt changes of the propeller loads and the PS rotational speed oscillations adversely affecting the internal combustion engines.

In the state $S_{2}$ increased frequency of manoeuvres must be taken into account, including reversing the engine sense of rotation. It is well known that engine reversals speed up the engine wear and tear process. The presented phenomena indicate dependence of the ICF event on the $\mathrm{S}_{1}$ and $\mathrm{S}_{2}$ states.

The ICF event is exceptionally dangerous when the ship is in the $\left(\mathrm{S}_{1} \cap \mathrm{S}_{3}\right)$ states. Ship, without propulsion in a strong storm in open sea, cannot weather, and it is threatened by capsizing. 
Sailing in restricted waters, i.e. in the states $S_{i},(i=3,4,5)$, is involved with possible contact collision with natural objects or with artifacts placed in those waters. Such possibility increases in the storm conditions. Increased probability of navigation errors in those states should also be taken into account.

Analysis of the physical nature of partial damage $C^{(i)},(i=1,2, \ldots, 7)$, leads to a conclusion as follows: 1) there exist different effects of REs and 2) it is very difficult to be estimated numerically. Experts can estimate it intuitively. A formal model of damage caused by the ICF type events is presented by formula (1). The form of those expressions is complex and indicates that estimations satisfactory in terms of accuracy, cannot be achieved in a formal way and possible identification of the conditional probabilities would be labour consuming.

$$
\left\{\begin{array}{c}
P_{t}\left\{C^{(1)} / I C F\right\}=P\{C\} P\left\{S_{1} / C\right\} P\left\{S_{2} / C \cap S_{1}\right\} P\left\{I C F / C \cap S_{1} \cap S_{2}\right\} \\
P_{t}\left\{C^{(2)} / I C F\right\}=P\{C\} P\left\{S_{1} / C\right\} P\left\{S_{3} / C \cap S_{1}\right\} P\left\{I C F / C \cap S_{1} \cap S_{3}\right\} \\
P_{t}\left\{C^{(3)} / I C F\right\}=P\{C\} P\left\{S_{1} / C\right\} P\left\{S_{4} / C \cap S_{1}\right\} P\left\{I C F / C \cap S_{1} \cap S_{4}\right\} \\
P_{t}\left\{C^{(4)} / I C F\right\}=P\{C\} P\left\{S_{1} / C\right\} P\left\{S_{5} / C \cap S_{1}\right\} P\left\{I C F / C \cap S_{1} \cap S_{5}\right\} \\
P_{t}\left\{C^{(5)} / I C F\right\}=P\{C\} P\left\{S_{2} / C\right\} P\left\{I C F / C \cap S_{2}\right\} \\
P_{t}\left\{C^{(6)} / I C F\right\}=P\{C\} P\left\{S_{4} / C\right\} P\left\{I C F / C \cap S_{4}\right\}, \\
P_{t}\left\{C^{(7)} / I C F\right\}=P\{C\} P\left\{S_{5} / C\right\} P\left\{I C F / C \cap S_{5}\right\} .
\end{array}\right.
$$

The PR of damage from the $\mathrm{C}$ subset is a total probability of partial damage $\mathrm{C}^{(\mathrm{i})} / \mathrm{ICF}$, $(i=1,2, \ldots, 7)$, i.e. the sum of respective probabilities in the time interval $\langle 0, t\rangle$ :

$$
\operatorname{PR}(\mathrm{t})=\mathrm{P}_{\mathrm{t}}\{\mathrm{C} / \mathrm{ICF}\}=\sum_{\mathrm{i}=1}^{7} \mathrm{P}_{\mathrm{t}}\left\{\mathrm{C}^{(\mathrm{i})} / \mathrm{ICF}\right\} \text {. }
$$

In equations (1), once conditional probabilities are replaced by unconditional probabilities, then estimation of the upper limit of risk $\mathrm{PR}_{u}(t)>P R(t)$ will be obtained.

\section{Subjective model of the propulsion risk}

Model (1) of PR is formally correct but is too detailed when it is seen as an object of expert estimation. This remark is particularly applicable to expressions where damage from the $\mathrm{C}$ subset is treated as condition. These are probabilities of the REs and it is rather unlikely that experts can estimate them correctly. A simpler model is presented here below.

The probability of ICF event identification method based on expert opinions is partly presented in [2]. The described example is PS of a container carrier operating in the North Atlantic between the ports of Central Europe and of the East Coast of North America. The probability of the failures causing loss of the ship propulsion function is modelled as a Homogeneous Poisson Process (HPP) presented in formula (3). In the investigations presented in [2], the annual frequency of ICF failures of the analysed container carrier PS is given within the range from 1 to 5. Probability distribution of the ICF numbers obtained from that formula is shown in Fig. 1.

$$
P\{I C F, t\}=P\left\{I C F, t^{(a)}\right\}=\left[\frac{\left(\lambda^{(a)} \kappa t\right)}{k !} e^{-\lambda^{(a)} \kappa t}\right], k=1,2, \ldots, K,
$$

where: $\mathrm{t}$ - PS operation time, $\mathrm{t}^{(\mathrm{a})}=-\mathrm{PS}$ active usage state equal to the time at sea, $\kappa$ - time at sea coefficient $(\kappa=\mathrm{t}(\mathrm{a}) / \mathrm{t}), \lambda(\mathrm{a})$ - rate of occurrence of the PS failures in the usage state, $\mathrm{k}=1,2, \ldots, \mathrm{K}-$ number of ICFs in the time interval $\langle 0, \mathrm{t}\rangle$.

Set $\mathrm{C}$ of damage categories (Tab. 1) is assumed as a complete set of disjoint events, which may follow an ICF event. The damage severity identification were performed based on expert opinions given in the procedure $\mathrm{A}$, in which experts compared pairwise the damage severities from the set $\mathrm{C}$ 
- effect of an ICF event. The damage severity probability vector is determined by the AHP method with the use of geometric scale of preference (Tab. 3) [13]. From the expert opinions, the weight coefficients of the individual damage severity categories can be determined. The coefficients fulfil the Kolmogorov axioms [3], and they may be interpreted as severity probabilities of each of the five damage categories. In this way, the probabilities of damage severity from the set $\mathrm{C}$ can be obtained as:

$$
P(S / I C F)=\left(p_{s_{1}}, p_{s_{2}}, \ldots, p_{s_{5}}\right)_{I C F} .
$$

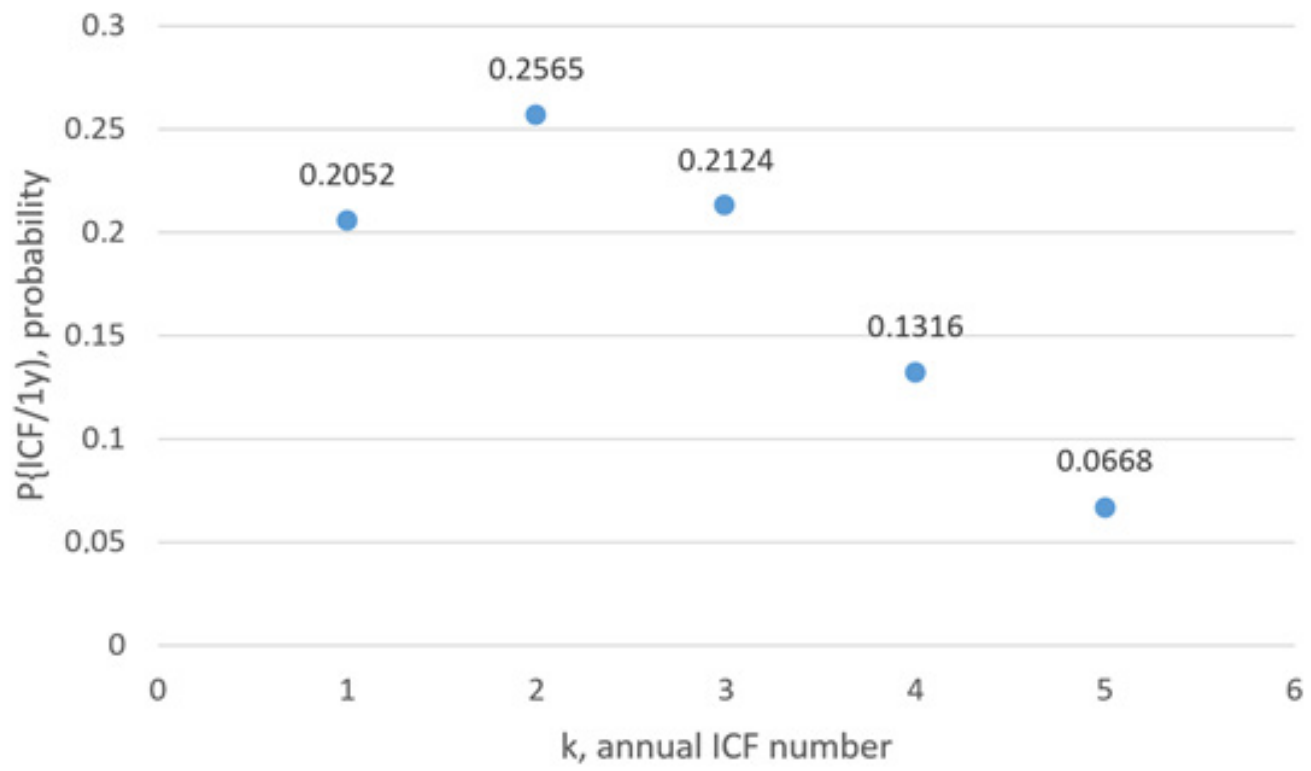

Fig. 1. Distribution of ICF number probability

In the procedure $\mathrm{B}$, occurrence chances of particular damage categories were evaluated by experts assigning a value from a chosen linguistic set: very small, small, average, great, and very great as shown in Tab. 5. These linguistic data were transferred into the intuitionistic fuzzy preference matrices and processed by using the intuitionistic fuzzy AHP [8]. In this way, the probabilities of damage occurrence from the set $\mathrm{C}$ can be obtained:

$$
P(C / I C F)=\left(p_{C_{1}}, p_{C_{2}}, \ldots, p_{C_{5}}\right)_{I C F},
$$

where: $p_{C j},(j=1,2, \ldots, 5), p_{C j},(j=1,2, \ldots, 5)=$ probability of $j$-th damage category occurrence, $\sum_{j=1}^{5} p_{C_{j}}=1$. They are conditional probabilities as the expert opinions pertained to damage followed by ICF occurrence. $\sum_{\mathrm{j}=1}^{5} \mathrm{p}_{\mathrm{Cj}}=1$.

The proposed method allows avoiding determining the partial damage probabilities from model (1) - only the ICF-C relations are determined. Disadvantage of the solution is impossibility of analysing the effect of ship operational state on the propulsion risk.

Further on the damage severities from the $\mathrm{E}=\{\mathrm{C} 1, \mathrm{C} 2\}$ subset will be dealt with. Damage of severity $\mathrm{C} 1$ or $\mathrm{C} 2$ can occur only once during a ship voyage. Its occurrence causes exclusion of the ship from operation - it may be sunk or may lose seaworthiness and undergo repairs. Such damage may occur after each ICF type PS failure. It takes place with conditional probabilities where the condition is occurrence of an ICF. We assume that the probability is independent of the ICF event consecutive number and is the same for all the ICF events in a given time interval $\langle 0, t\rangle$.

$\mathrm{PR}$ is a probability of damage with severity taken from the E subset, which may occur after a series of ICF type PS failures. Such damage may take place after a consecutive failure if it did not happen after preceding failures. It is a chain of events ending with damage E. The damage risk is modelled by the vector of damage caused by consecutive ICF type events: 


$$
P R(t)=\left[P(E / I C F) P(S / I C F) \sum_{k=1}^{K} P_{k}(I C F, t)\{1-P(E / I C F)\}^{k-1}\right],
$$

where: $k=1,2, \ldots, K$ - number of ICFs in the time interval $\langle 0, t\rangle$.

\section{Case study}

The object of the case study is a container carrier operating in the North Atlantic. It is assumed that the ship is fitted with a conventional propulsion system consisting of a low-speed internal combustion engine and directly connected screw propeller. This study is a continuation of the analyses presented in [2].

Experts in the described case were 30 ship engineers, carefully chosen, with many years' marine experience. They had a difficult task, as their experience did not include the extreme damage events with severities from the $\mathrm{C}$ subset (the rare events). Experts could have experienced only circumstances for such damage, i.e. ICF events in states $S_{j},(j=1,2, \ldots, 5)$. Opinions on the conditional damage occurrence should be treated as intuitive.

In the experiment, experts received questionnaires with the following information: aim of the investigation, appeal for reliable filling the questionnaire in, definitions of the events and states named in the questionnaire (ICF, C, $\mathrm{S}_{1}, \ldots, \mathrm{S}_{5}$ ) and of the "chance" and "preference" notions and also the respective tables to be filled in. Due to formal reasons, questions in the tables cover the complete set of damage severities mentioned in Tab. 1.

Tab. 3. Geometrical scale of preference data

\begin{tabular}{|c|c|l|l|}
\hline \multicolumn{5}{|c|}{ AHP geometrical scale } \\
\hline$s_{i}$ & $I(s)$ & \multicolumn{1}{|c|}{$r(s)$} & \multicolumn{1}{c|}{ Name of preference } \\
\hline$s_{\mathrm{o}}$ & 0 & 1 & equally important \\
\hline$s_{2}$ & 2 & 2 & moderately more important \\
\hline$s_{4}$ & 4 & 4 & strongly more important \\
\hline$s_{6}$ & 6 & 8 & demonstratively more important \\
\hline$s_{8}$ & 8 & 16 & extremely more important \\
\hline$s_{-2}$ & -2 & 0.5 & moderately less important \\
\hline$s_{-4}$ & -4 & 0.25 & strongly less important \\
\hline$s_{-6}$ & -6 & 0.125 & demonstratively less important \\
\hline$s_{-}-$ & -8 & 0.0625 & extremely less important \\
\hline
\end{tabular}

In the procedure A, the obtained data were processed by the AHP method with the use of geometrical scale [13], which the characteristics are given in Tab. 3 and described as follows:

$$
r\left(s_{i}\right)=c^{I\left(s_{i}\right) / 2} \mathrm{r}(\mathrm{s})=(\sqrt{\mathrm{c}})^{\mathrm{I}(\mathrm{s})} \text {, }
$$

where: $I\left(s_{i}\right)=\mathrm{I}(\mathrm{s})=$ index of the preference variable $s_{i} ; c=2$ - parameter.

To each pair comparison $s_{i}$ made by expert, a value $r$ was assigned from the set $\mathrm{r}(\mathrm{s})=\{1,2,4, \ldots, 0.0625\}$ as shown in Tab. 3, which expresses its individual linguistic preference. Then the matrix $\mathrm{R}=\left(\mathrm{r}_{\mathrm{ij}}\right)_{5 \times 5}$ of the pairwise comparison judgments was obtained and the normalized vector of the damage severity probability $(S / I C F)=\left(p_{s_{1}}, p_{s_{2}}, \ldots, p_{s_{5}}\right)_{I C F}$, where $p_{-}(..) p_{\ldots} \ldots$ - weight coefficients of the particular damage severity, was determined by using the logarithmic least square approach $[6,11]$ as the priority method.

In the procedure $\mathrm{B}$, the experts revealed their opinions on the chances of damage occurrence under condition of the seagoing ship propulsion system ICF failure, expressed in the form of 
linguistic values very small, small, average, great and very great as shown in [8]. These linguistic data were transferred into the intuitionistic fuzzy preference matrices and processed by using the intuitionistic fuzzy AHP [8]. In this way, normalized vector of the damage occurrence probabilities was obtained:

$$
P(C / I C F)=\left(p_{C_{1}}, p_{C_{2}}, \ldots, p_{C_{5}}\right)_{I C F},
$$

$\mathrm{p}_{\mathrm{A}, \mathrm{ICF}}=\left(\mathrm{p}_{\mathrm{A} 1}, \mathrm{p}_{\mathrm{A} 2}, \ldots, \mathrm{p}_{\mathrm{A} 5}\right), \mathrm{p}_{\mathrm{B}, \mathrm{ICF}}=\left(\mathrm{p}_{\mathrm{B} 1}, \mathrm{p}_{\mathrm{B} 2}, \ldots, \mathrm{p}_{\mathrm{B} 5}\right)$, where $\mathrm{p}_{-}(..) \mathrm{p}_{\ldots}$ - weight coefficients of the particular damage occurrence.

Probabilities of damage severity and occurrence from the $\mathrm{C}$ set (shown in Fig. 2) were determined from the expert opinions elicited through the above presented procedures (A and B). Results of both procedures correspond to the character of the analysed phenomenon: occurrence probability of less severe damage is greater than that of more severe damage and severity probabilities of less severe damage category is smaller than that of more severe one.

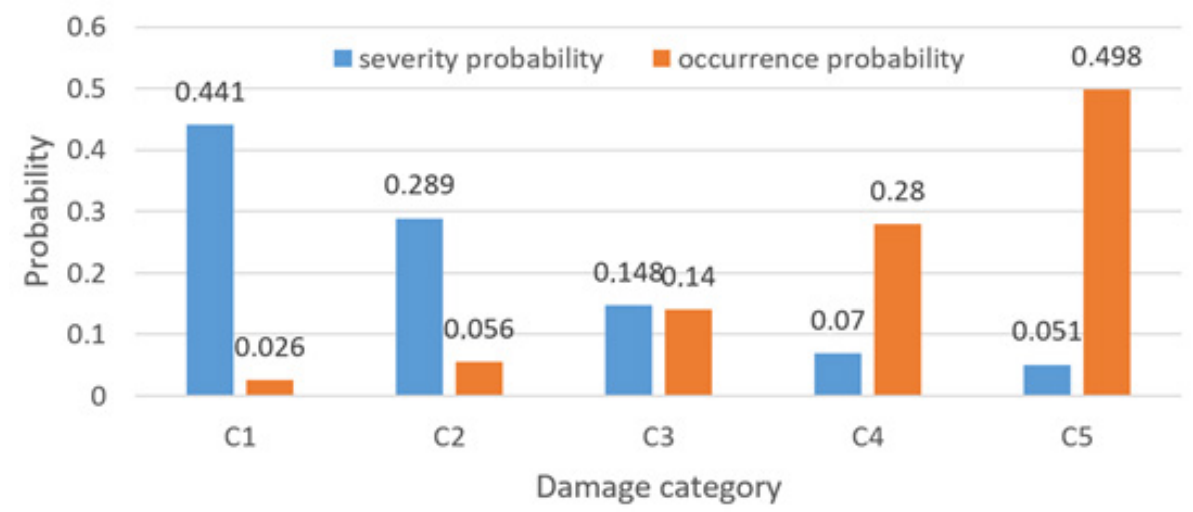

Fig. 2. Conditional probability of damage severity and occurrence

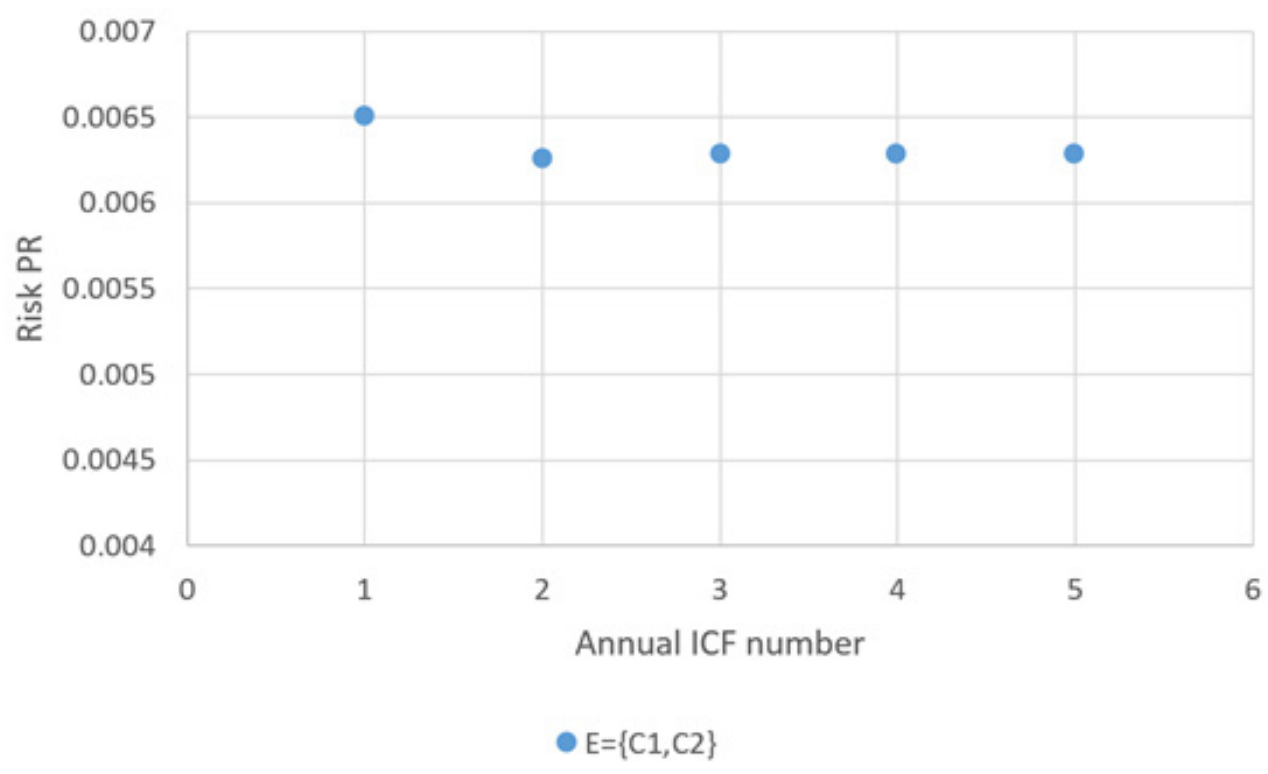

Fig. 3. Risk of severity damage to ship

Risk PR of damage category from the E subset determined by formula (6) is presented in Fig. 3. Formally, the probability of the occurrence of severe damages increased due to summation of the probabilities of consecutive ICF failures multiplied by the probabilities of the nonoccurrence of damage. The effect of the latter decreased as their number increased. The PR as a multiply of severity and occurrence probabilities takes a maximum at the first ICF event with severe damage category E. Then it slows down approaching a stable value. 
Probability of ICF events is estimated at about $20 \%$ of ship accidents and frequency severe consequences of propulsion system failures is estimated at approximately $0.7 \%$ of the ship population annually ( 7 ships per 1000 in a year). However, it must be taken into account that the subset damage E does not fully correspond to the "severe engine failure" notion - it is broader as it includes human and ecological damage. According to the Helcom report in 2013 [4], there were 150 accidents in total 350000 ship crossings in the used passage lines of the Baltic sea, while 5\% of them were severe damages to ship, $19 \%$ of them were caused by technical failures providing the frequency severe consequences of propulsion system failures at about $0.9 \%$ of the ship population. Hence, the obtained results seem to be consistent with the current data and literature on the ship internal combustion engine failures [9]. The investigation results may be numerically recorded in the form of a vector of $(\mathrm{k}, \mathrm{PR})$ pairs:

$$
\boldsymbol{P R}(1 \mathbf{y})=[(1,0.0065),(2,0.0063),(3,0.0063),(4,0.0063),(5,0.0063)] .
$$

\section{Błąd! W tym miejscu powinna wystąpić cyfra.Conclusions}

Occurrence of damage as a consequence of the loss of ship propulsion function is a rare event. Probability of damage within a specific time interval is the ship propulsion risk. Data for the propulsion risk estimation was acquired from the expert opinion elicitation. The risk determination procedures are presented. They consist in defining the damage severity category as an effect of the loss of ship propulsion function event and in various scenarios of damage occurrence. Elicitation was carried out by two methods: pairwise comparing of the damage severity preferences and chances of damage occurrence with determined severities. The acquired opinions were processed by the AHP method and fuzzy method. Conditional probabilities of the damage severity and occurrence were determined with the condition as loss of the ship propulsion function.

The example of expert investigation was a virtual container carrier operating in the North Atlantic. Elicitation was performed with $\mathrm{A}$ and $\mathrm{B}$ procedures. The acquired opinions were processed by the AHP method with the use of the geometrical scale. The ship propulsion risk was determined, i.e. probability of severe damage after loss of the propulsion function The investigation results are in compliant with the phenomenological nature and current statistical data.

The results would support planning of further research work on the application of expert methods to safety control of the technical systems in general and of the sea-going ships in particular.

\section{References}

[1] Admiralty Ocean Passages for the World, Fifth ed. Admiralty Charts and Publications; UK 2004.

[2] Brandowski, A, Nguyen, H, Frackowiak, W, Podsiadlo, A., Risk estimation of the sea-going ship casualty as the consequence of propulsion loss, Proceedings of ESREL Conference 2009.

[3] Cooke, R. M., Experts in Uncertainty, Oxford University Press, Oxford, New York 1991.

[4] HELCOM (2014), Annual report on shipping accidents in the Baltic Sea in 2013.

[5] Hurricane Centre Section of the Environment Canada's Website (http://www.nhc.noaa/gov).

[6] Kwiesielewicz, M., The analytic hierarchy decision process. Fuzzy and not fuzzy paired comparision, System Research Institute PAN. Warsaw 2002.

[7] Modarres, M, Kaminskiy, M, Krivtsov, V., Reliability Engineering and Risk Analysis, Marcel Dekker, New York 1999.

[8] Nguyen, H., An application of intuitionistic fuzzy analytic hierarchy process method in ship system risk estimation, Journal of KONES Powertrain and Transport, Vol. 23, No. 1, pp. 365-372, 2016.

[9] Podsiadło, A., Analysis of failure engine for main ship propulsion, Internal Study of Gdynia Maritime University, Gdynia 2008. 
[10] Resolution A 849(20), Code for the investigation of marine casualties and incidents, IMO 1997.

[11] Saaty, T. L., The analytic hierarchy process, McGraw Hill, New York 1980.

[12] Tanava, M., A subjective assessment of alternative mission architectures for the human exploration of Mars at NASA using multicriteria decision making, Computers \& Operations Research, Vol. 31, Elseviere, 2004.

[13] Yucheng, D., Yinfeng, X., Hongyi, L., Min, D., A comparative study of the numerical scales and the prioritization methods in AHP, European Journal of Operational Research, Vol. 186. Elseviere, 2008.

Manuscript received 10 December 2018; approved for printing 12 March 2019 